\title{
Problematização do trabalho em equipe em enfermagem: relato de experiência
}

\author{
Problematization of teamwork in nursing: experience report \\ Problematización del trabajo en equipo en la enfermería: relato de experiencia
}

\author{
Marília Doriguello Bergamim', Cláudia Prado" \\ ' Universidade de São Paulo, Escola de Enfermagem (Graduanda). São Paulo-SP, Brasil. \\ "Universidade de São Paulo, Escola de Enfermagem, Departamento de Orientação Profissional. São Paulo-SP, Brasil.
}

Submissão: 03-01-2011 Aprovação: 16-03-2013

\begin{abstract}
RESUMO
Relato de experiência em relação ao trabalho em equipe, a partir da observação da realidade do estágio curricular em enfermagem. Realizou-se dinâmica de grupo com a equipe de enfermagem da clínica cirúrgica de um hospital público de São Paulo, com participação voluntária de oito auxiliares de enfermagem e utilizou-se, como base teórica, a Metodologia da Problematização, que objetiva a compreensão da realidade para nela intervir e transformá-la. Observou-se deficiência na autocrítica desses participantes, pois apontaram os problemas em relação ao trabalho em equipe sempre decorrentes da falta de cooperação de outros colegas, em detrimento de atitudes pessoais. Essa estratégia contribuiu de maneira significativa para a reflexão de comportamentos, atitudes, valores e crenças indispensáveis à formação do enfermeiro.
\end{abstract}

Descritores: Enfermagem; Estágio Clínico; Equipe de Enfermagem.

\begin{abstract}
This is a report of experience in relation to teamwork, from the observation of the reality of clinical clerkship in nursing. It was held group dynamics with the nursing staff of the surgical clinic of a public hospital in Sao Paulo, with participation by eight nursing assistants and was used as a theoretical basis, the methodology of Curriculum, aimed at understanding reality it to intervene and transform it. Deficiency was observed in these participants self-criticism, as pointed out the problem in terms of teamwork always due to lack of cooperation of other colleagues, rather than the attitudes. This strategy has contributed significantly to the reflection of behaviors, attitudes, values and beliefs essential to nursing education.
\end{abstract}

Key words: Nursing; Clinical Clerkship; Nursing Staff.

\section{RESUMEN}

Informe de la experiencia en relación con el trabajo en equipo, de la observación de la realidad de las prácticas clínicas de enfermería. Dinámica de grupo celebradas con el personal de enfermería de la clínica quirúrgica de un hospital público en Sao Paulo, con la participación de 8 auxiliares de enfermería y fue utilizado como una base teórica, la metodología del plan de estudios, destinado a comprender la realidad a intervenir y transformarla. La deficiencia se observó en estos auto participantesla crítica, como ha señalado el problema en términos de trabajo en equipo siempre se debe a la falta de cooperación de otros colegas, en vez de las actitudes. Esta estrategia ha contribuido significativamente a la reflexión de los comportamientos, actitudes, valores y creencias esenciales para la educación de enfermería.

Palabras clave: Enfermería; Prácticas Clínicas; Equipe de Enfermería. 


\section{TRABALHO EM EQUIPE}

O trabalho é o meio através do qual o homem se relaciona com o homem, utilizando a natureza para construir sua história e transformá-la, estabelecendo mediações para ambos se modificarem. $\mathrm{O}$ trabalho da enfermagem é considerado como um processo particular do trabalho coletivo em saúde, conferindo a este um caráter subsidiário e complementar, transformando então o mesmo objeto de trabalho, que é o corpo humano individual e coletivo ${ }^{(1)}$.

O objeto de trabalho em saúde tem muitas dimensões, como a biológica, psicológica, social e cultural, possibilitando a construção ampliada à atenção integral, suprindo as necessidades em saúde nas variadas intervenções profissionais. O processo de trabalho em saúde possui um aspecto de ser um serviço que se funda numa inter-relação pessoal grande, por não realizar o serviço em cima de coisas, objetos, dá-se sobre pessoas, e essa pessoa tem que contribuir com o processo, para que o mesmo tenha eficácia e eficiência, a fim de alcançar objetivos iniciais ${ }^{(1)}$.

Uma característica particular do processo de trabalho em enfermagem é a fragmentação das funções, ou seja, a existência de auxiliares de enfermagem, técnicos de enfermagem e enfermeiros dentro da categoria profissional Enfermagem.

A divisão do trabalho de enfermagem expressa, desde sua a origem, a marca do trabalho coletivo, em virtude do processo de enfermagem não ter a possibilidade de ser gerado por uma pessoa só, tal como ocorre com outros trabalhos especializados, como medicina, psicologia, fisioterapia, serviço social. Dada a existência de um conjunto de agentes, fazem-se necessárias ações de coordenação e supervisão, de gerência.

$\mathrm{O}$ que configura o trabalho em equipe?

O serviço de saúde especializado tende à fragmentação do cuidado prestado ao paciente, configurando uma teia de ações executadas por diferentes agentes, que necessitam de articulação. Na atualidade, a nenhum trabalhador de saúde em separado, cabe a possibilidade de atender às demandas de saúde apresentadas pelos pacientes, ou mesmo, por um único usuário em particular; por isso, torna-se necessário que os profissionais reconheçam as conexões que existem entre as diversas atividades executadas e as tomem em consideração, integrando suas ações ${ }^{(2)}$.

Dessa forma, faz-se necessário articular as diversas ações realizadas no interior de um setor, unidade, ou serviço, bem como os setores, unidades e serviços entre si.

Geralmente observa-se a existência de equipe apenas no sentido de coexistência de vários profissionais numa mesma situação de trabalho, compartilhando o mesmo espaço físico e a mesma clientela, ou seja, não necessariamente integrados.

Existem dois tipos diferentes de trabalho em equipe: a equipe integração, na qual se observa a busca de articulação das ações e de integração dos profissionais; e a equipe agrupamento, em que ocorrem a justaposição de ações e o mero agrupamento de agentes ${ }^{(1-2)}$.

Quando a equipe alcança algum grau de integração, expressa uma relação recíproca, de mútua influência, entre trabalho e interação. Sendo assim, a interação não faz parte apenas do próprio processo de trabalho e torna-se uma ação produtiva e interação social.

As principais características de uma equipe integrada consistem em flexibilizar a divisão do trabalho; preservar as diferenças técnicas entre os trabalhos especializados; questionar a desigualdade na valoração dos distintos trabalhos e respectivos agentes; descentralizar a tomada de decisão na equipes e no serviço, favorecendo o partilhar de decisões sobre questões relacionadas à dinâmica de trabalho; exercer a autonomia profissional, tomando, em consideração, a interdependência das diversas áreas profissionais; e construir um projeto assistencial comum ${ }^{(2)}$.

Estas características do trabalho em equipe necessitam, para sua efetivação, comunicação e integração entre os agentes envolvidos, no sentido de construírem consensos e acordos. Esse processo permite, ao longo de uma experiência trabalho em conjunto construir um projeto assistencial comum, o que poderia ser caracterizado com um trabalho em equipe no sentido integral da expressão.

Nesse sentido, na formação do enfermeiro é imprescindível a construção desses saberes e a Escola de Enfermagem da Universidade de São Paulo contempla na disciplina de Estágio Curricular de Administração em Enfermagem um espaço de reflexão e aprofundamento sobre o trabalho em equipe. Assim, este estudo foi motivado a partir da observação da realidade encontrada durante esse estágio em relação ao trabalho em equipe na enfermagem.

\section{PLANEJAMENTO DA INTERVENÇÃO}

O questionamento acerca da temática do Trabalho em Equipe surgiu através da observação cotidiana, durante o período do estágio curricular em enfermagem, da dinâmica dos relacionamentos interpessoais dos integrantes do grupo de enfermagem e, consequentemente, dos conflitos advindos desse mesmo processo.

Foi planejada uma dinâmica de grupo com a equipe de enfermagem da clínica cirúrgica de um hospital público da cidade de São Paulo. Essa dinâmica teve como base teórica a Metodologia da Problematização, que objetiva a compreensão da realidade para intervir nela e transformá-la. A habilidade de problematizar é vista como a capacidade de relacionar de forma coerente e seqüencial três momentos: identificação de um problema, busca de explicação e proposição de soluções $^{(3)}$. A Problematização encontra, nas formulações de Paulo Freire, um sentido de inserção crítica na realidade para dela retirar os elementos que conferirão significado e direção às aprendizagens. No movimento ação-reflexão-ação são elaborados os conhecimentos, considerando a rede de determinantes contextuais, as implicações pessoais e as interações entre os diferentes sujeitos que aprendem e ensinam.

Nesse sentido, a idéia básica do pensamento de diversos teóricos da área de educação está centrada no desenvolvimento da capacidade de raciocínio e espírito crítico do homem. Essa compreensão remete a uma prática baseada na liberdade de elaborar as próprias certezas, os próprios conhecimentos, as próprias regras morais, reconhecendo nas 
situações concretas, as circunstâncias que conduzem a experiências que produzem o conhecimento além de valorizar e promover a aprendizagem através da experiência vivenciada no cotidiano ${ }^{(4)}$. Assim, nessas circunstâncias, emergem as dimensões problematizadoras, as quais assumem a construção do conhecimento como traço definidor da apropriação de informações e explicação da realidade, tomando-a como ponto de partida e chegada do processo de aprendizagem ${ }^{(5)}$.

Vale ressaltar que uma proposta problematizadora tem como propósitos que o sujeito seja ativo no seu processo de problematizar porque precisa ter uma situação autêntica de experiência na qual esteja interessado; as atividades devem ter propósitos definidos, com clareza e objetividade; o sujeito precisa aprender a observar para utilizar as informações e instrumentos disponíveis; o resultado do trabalho deve emergir em algo concreto; o sujeito necessita ter a oportunidade de comprovar as idéias que tenha tido, por meio da sua aplicação e, por fim, a aprendizagem deve partir da problematização dos conhecimentos prévios do sujeito.

\section{PROBLEMATIZAÇÃO DO TRABALHO EM EQUIPE NA ENFERMAGEM}

Foi feito um convite prévio impresso a todos integrantes da equipe de enfermagem para participarem da dinâmica, que aconteceu no dia 23 de outubro de 2009, na sala de estudos da unidade, teve duração de 35 minutos, contou com a participação voluntária de oito auxiliares de enfermagem e ocorreu em três fases:

$\checkmark$ Primeira fase: No início da dinâmica, aconteceu uma estratégia de aquecimento na qual os participantes escolheram uma foto entre várias disponibilizadas, as quais representavam pessoas de etnias distintas, provenientes de jornais/ revistas e disponibilizadas sobre uma mesa. A partir disso, justificaram essa escolha e exteriorizaram os sentimentos e emoções provocados pela primeira visualização das imagens. Também foram questionados acerca de determinados valores e crenças, promovendo uma reflexão sobre os pré-julgamentos inferidos da aparência das pessoas num primeiro contato e a implicação desses num convívio em equipe.

$\checkmark$ Segunda fase: Foram distribuídas três situações-problema diferentes entre os grupos formados e houve um período para leitura e apreciação das situações descritas. Em segui$\mathrm{da}$, os participantes socializaram com o restante do grupo as situações apresentadas, e a partir disso, iniciou-se a discussão sobre as dificuldades do trabalho em equipe, os fatores de desgaste e fortalecimento no relacionamento interpessoal e as possíveis soluções para tornar a convivência em equipe mais harmônica.

$\checkmark$ Terceira fase: O debate foi concluído com a leitura e discussão de um texto ${ }^{(1)}$, pelos participantes, o qual versa sobre o trabalho em equipe, suas dificuldades e implicações.

\section{AVALIAÇÃO DA INTERVENÇÃO}

A avaliação da dinâmica foi realizada pelos participantes através do preenchimento de um formulário que indagava quanto às emoções e sentimentos trazidos à tona pela dinâmica.

Houve uma participação expressiva dos integrantes da equipe de enfermagem na dinâmica. $\mathrm{O}$ entrosamento entre os participantes foi perceptível, assim como a desinibição ao expressarem valores, crenças e opiniões individuais.

A maioria dos participantes afirmou ter uma impressão pré-concebida baseada na aparência física num primeiro contato com um novo elemento no grupo e, conforme a convivência no dia-a-dia se desenvolve, essa concepção dá lugar a um “julgamento" baseado nas atitudes e ações ao invés de somente da aparência.

Em relação aos conflitos e dificuldades do trabalho em equipe, o grupo apontou como possível causa a não colaboração dos colegas de equipe, o que torna, segundo os mesmos, as tarefas e a convivência desgastantes. Notou-se, independentemente das situações, que os problemas apontados ocorriam sempre por falta de cooperação apenas de outros colegas, evidenciando-se um déficit na realização de auto-crítica e avaliação dos participantes. Nesse mesmo sentido, as soluções propostas relacionavam-se com a mudança de comportamento e atitudes de outros colegas, em detrimento a mudanças individuais.

\section{CONSIDERAÇÕES FINAIS}

Apesar dos resultados obtidos não terem sido surpreendentes, acredita-se que a estratégia da dinâmica baseada na problematização dos fatos contribuiu de maneira significativa para a retomada de comportamentos, atitudes, valores e crenças indispensáveis ao bom andamento do trabalho em equipe.

Compreender o real significado do trabalho em equipe requer uma permanente reflexão sobre as práticas de enfermagem em qualquer segmento de atuação, visto que essa é uma ferramenta essencial no trabalho. Um bom atendimento em saúde com qualidade e eficiência requer envolvimento coletivo dos profissionais, fato este que aponta a importância de uma análise acurada das relações interpessoais no desempenho das equipes ${ }^{(6)}$.

Vale destacar que o estágio curricular tem sido apontado por diversos autores ${ }^{(7-8)}$ como um momento de crucial importância no processo de formação profissional, e que, tanto o docente quanto o enfermeiro atuante no campo da prática, tem significativa influência no desenvolvimento de habilidades, técnicas e atitudes do estagiário de Enfermagem. Essa fase da formação acadêmica possibilita não só a integração dos saberes apreendidos nas diversas disciplinas oferecidas durante o curso de graduação, como permite ao estudante o exercício da construção de sua autonomia e responsabilidade nesta etapa de transição de identidade do futuro enfermeiro. 


\section{REFERÊNCIAS}

1. Peduzzi M. Equipe multiprofissional de saúde: a interface entre trabalho e interação. Interface Comun Saúde Educ 2000;4(6):151.

2. Kurcgant $\mathrm{P}$, coordernadora. Gerenciamento em enfermagem. Rio de Janeiro: Guanabara Koogan; 2005.

3. Zanotto MAC. A formação contínua como possibilidade do aprimoramento da ação de problematizar: análise de uma proposta voltada para professores atuantes em Educação Especial. São Carlos. Tese [Doutorado em Educação Especial] -Universidade Federal de São Carlos; 2002.

4. Pereira EA, Martins JR, Alves VS, Delgado El. A contribuição de John Dewey para a educação. Revista Eletrônica de Educação 2009;3(1):154-161.
5. Batista N, Batista SH, Goldenberg P, Seiffert O, Sonzogno MC. O enfoque problematizador na formação de profissionais da saúde. Rev Saúde Pública 2005;39(2):231-7.

6. Abreu LO, Munar DB, Queiroz ALB, Fernandes CNS. O trabalho de equipe em enfermagem: revisão sistemática da literatura. Rev Bras Enferm 2005;58(2): 203-207.

7. Bousso RS, Merighi MAB, RolimMA, Riesco MLG, Angelo $M$. Estágio curricular em enfermagem: transição de identidades. Rev Esc Enf USP 2000;34(2):218-25.

8. Costa LM, Germano RM. Estágio curricular supervisionado na Graduação em Enfermagem: revisitando a história. Rev Bras Enferm 2007;60(6):706-710. 